\title{
Evaluation of Low Temperature Induced Mutants of Cucumber green mottle mosaic virus for Cross-protection in Cucurbits
}

\author{
Asad Ali ${ }^{1,2 *}$, Musharaf Ahmad ${ }^{2}$, Hisashi Nishigawa ${ }^{1}$ and Tomohide Natsuaki ${ }^{1}$ \\ ${ }^{1}$ Faculty of Agriculture, Laboratory of Plant Pathology, Utsunomiya University, Mine Campus, Japan \\ ${ }^{2}$ Department of Plant Pathology, The University of Agriculture, Peshawar, Pakistan
}

\begin{abstract}
Cucumber green mottle mosaic virus has been reported as the most prevalent and dominant virus infecting cucurbit crops in KPK, Pakistan. Inoculated plants of $C$. sativus were treated at low temperature to generate and select mild strain of CGMMV for cross protection. Among 200 inoculated plants during mild strain selection, only two were showing no symptoms and were also strongly positive in serological assay as well as in electron microscopy. These two isolates, designated as Pk-47 and Pk-81, were selected for subsequent experiments on cross-protection.

In greenhouse experiments, the control plants started developing symptoms just 5 days after inoculation and were exhibiting severe symptoms in 10-12 days post challenge inoculation. Plants inoculated with Pk-47 isolate initially developed very mild symptoms that disappeared in one week post inoculation period. In cross-protection test, with the two selected isolates, symptoms developed in plants that were challenge-inoculated 5 or 7 days post protection-inoculation. Those plants that were given challenge-inoculation 10 days after the protection-inoculation did develop some mild symptoms, but later on they showed recovery. In all other treatments (challenge-inoculation done after 15, 20 and 25 days post protection-inoculation) both the Pk-47 and Pk-81 mild isolates were exhibiting convincing protection abilities to control the severe strain of CGMMV-Pk. The effectiveness of the cross-protection was evaluated at three different temperatures $\left(17-22^{\circ} \mathrm{C}, 22-27^{\circ} \mathrm{C}\right.$ and $\left.27-32^{\circ} \mathrm{C}\right)$, and it was observed that it worked equally well under all the experimental conditions. Among the two isolates, protection abilities of $\mathrm{Pk}-81$ seemed to be more promising comparing to Pk-47. All the plants remained symptom-less, for almost two months, after the challenge inoculation. The experimental results revealed that protection inoculation at least 15 days prior to challenge inoculation will serve better.
\end{abstract}

Keywords: Cucurbit; CGMMV; Incidence; Tobamovirus; Pakistan

\section{Introduction}

It has long been known that the activity of one plant virus can prevent or delay the infection of closely related viruses [1]. The phenomenon that was coined cross-protection, pre-munity, acquired immunity, antagonism, cross immunization or interference, needs the former virus to be established for conferring the effective resistance. It is a type of induced resistance, developed in plants, by the systemic infecting virus against very closely related strain. Ideally, the protecting strain is not aggressive, but inhibits the pathogenetic effect of the super-infecting strain introduced by challenge inoculation [2,3]. It was described as early as 1930s, and was independently confirmed by several virologists. Cross-protection has also been demonstrated for other classes of plant pathogens and at times it was believed to be analogous to the immunity developed in mammals following vaccination, although its mechanism does not involve the formation of antibodies [4].

Palukaitis and Zaitlin [5] proposed that the positive sense RNA of protecting viruses would sequester the minus-strand of super-infecting virus strain, provided they have homology high enough to allow the annealing of the two strands. This annealing of negative strand also further blocks the replication of incoming virus. It was only this model that could explain the protection offered by naked RNA or viroids, and also, it justify why high level of homology is required to induce this response. Several lines of evidences indicate that RNA-based protection is derived from a nucleotide (nt) sequence-specific host defense mechanism, termed as post-transcriptional gene silencing (PTGS) that targets viral RNAs for destruction [6,7] demonstrating that PTGS is a common plant defense response active against diverse viruses and likely to play an important role in cross-protection. Data presented by different scientists also revealed that pre-expression of viral proteins play an important role in cross-protection. The relative importance of the different mechanisms may be a function of the viruses and the particular host species. Rezende et al., [8] suggested that the host may play a role in cross-protection between tobamoviruses.

Cross-protection has effectively been used against Papaya ringspot virus (PRSV) [9-11], Watermelon mosaic virus (WMV) [12], Cucumber mosaic virus (CMV) [13-15], Tobacco mosaic virus (TMV) [16-18], Citrus tristeza virus (CTV) [19], Zucchini yellow mosaic virus (ZYMV) [20], Cowpea mosaic virus (CPMV) [21] and Tomato mosaic virus ( $\left.\mathrm{T}_{\mathrm{o}} \mathrm{MV}\right)[22]$.

Etiology of the viral disease of cucurbit crops, prevalent in the cucurbit growing regions of Pakistan, clearly indicates the dominance of Cucumber green mottle mosaic virus (CGMMV). This high incidence could be attributed to the contact transmission of the virus, coupled with poor phytosanitary measures prevalent in the area. This necessitates testing of possible control strategies to eliminate the disease from the cucurbit growing areas. We are reporting here the cross-protection offered by mild isolate of CGMMV-Pk, induced by low temperature treatment, against the severe strain. Our efforts resulted in selection of two isolates, which were multiplying at high rate

*Corresponding authors: Ali A, Faculty of Agriculture, Laboratory of Plant Pathology, Utsunomiya University, Mine Campus, Japan, Tel: 92919218390; E-mail: asadjp2005@yahoo.com

Received November 29, 2014; Accepted April 25, 2015; Published May 08, 2015

Citation: Ali A, Ahmad M, Nishigawa H, Natsuaki T (2015) Evaluation of Low Temperature Induced Mutants of Cucumber green mottle mosaic virus for Crossprotection in Cucurbits. J Plant Pathol Microbiol S3: 010. doi:10.4172/2157-7471. S3-010

Copyright: ( 2015 Ali A, et al. This is an open-access article distributed under the terms of the Creative Commons Attribution License, which permits unrestricted use, distribution, and reproduction in any medium, provided the original author and source are credited. 
and were almost symptom-less in the inoculated plants. They offered effective protection, when challenge inoculated by the severe parent virus. As CGMMV is a contact transmitted virus, hence it will be easy to inoculate the seedlings with very little efforts and expenditures and hence will prove to any effective tool in devising an effective integrated control program for this menace.

\section{Materials and Methods}

\section{Virus isolate}

The CGMMV-Pk was isolated from Lagenaria siceraria samples collected at Khyber Pakhtunkhwa Province, Pakistan in 2002 and was maintained on mechanically inoculated plants of Cucumus sativus in insect proof greenhouse at Utsunomiya University, Japan. Mechanical inoculations were performed by rub inoculating the healthy C. sativus plants as described previously (Ali et al.). The plants were kept in greenhouse at $22-27^{\circ} \mathrm{C}$ with supplemented fluorescent lights.

\section{Local lesion host assay}

Chenopodium amaranticolor, C. quinoa, Nicotiana benthamiana, N. Glutinosa, N. Rustica, C. sativus and Vigna unguiculata were mechanically inoculated as described previously (Ali et al.) in an attempt to find out any reasonable local lesion hosts for mild strain selection, after the low temperature treatment.

\section{Mild strain selection at low temperature}

The inoculated plants of $C$. sativus were kept in greenhouse at a temperature of $\left(12-16^{\circ} \mathrm{C}\right)$ for 45 days. Meanwhile, healthy seeds of $C$. sativus were germinated in 200 plastic pots, each having two seeds, to raise the seedlings for mild strain selection. After germination thinning was done to reduce the number of seedling to one each pot. Mechanical inoculation was done by grinding $1 \mathrm{~g}$ leaf in $50 \mathrm{ml}$ of $0.05 \mathrm{M}$ potassium phosphate buffer, $\mathrm{pH} 7.5$ and test plants were rub inoculated on carborundum ( $600 \mathrm{mesh})$ dusted leaves. The plants were kept in greenhouse at $22-27^{\circ} \mathrm{C}$ with supplemented fluorescent lights. This temperature was previously evaluated as best for replication and symptom expression in C. sativus plants. The plants were grown for more than 6 weeks after inoculation. Indexing was started routinely after $10 \mathrm{dpi}$ and any plant showing symptoms was discarded.

\section{Serological assay}

All the remaining plants were tested for the presence of CGMMV using the dot immuno-binding assay (DIBA) protocol [23]. The reaction was recorded visually by the intensity of the colour. Only those plants having high concentration of virus particles and no visible symptoms were selected for cross-protection test.

\section{Electron microscopy}

Electron microscopy was also done for the selected samples to confirm the results of serological assay. Sap from infected leaves was coated on carbon-formvar coated grids as described previously [24] and were examined with JEOL 100S electron microscope.

\section{Cross-protection test}

C. sativus seedlings were mechanically inoculated with the selected isolates (hereafter termed $\mathrm{Pk}-47$ and $\mathrm{Pk}-81$ ) by rub inoculation as described previously by Ali et al., [24]. Infection was confirmed by DIBA assay 10 days after inoculation. Severe parent isolate that was used for mild isolate induction was challenge inoculated. Infectivity of the extract was determined by inoculation of healthy $C$. sativus seedlings. Challenge inoculation was applied on upper leaf 5, 7, 10, 15, 20 and 25 days after the inoculation of mild isolate. Three different temperatures $\left(17-22^{\circ} \mathrm{C}, 22-27^{\circ} \mathrm{C}\right.$ and $\left.27-32^{\circ} \mathrm{C}\right)$ were tried for cross-protection assay and at each temperature three plants were used. Breakdown of the protection was judged by the appearance of typical severe mosaic symptoms on test plants, which were kept in the greenhouse for at least two months, after challenge inoculation.

\section{Results}

\section{Selection of mild strains}

Cucumber green mottle mosaic virus has been reported as the most prevalent and dominant virus infecting cucurbit crops in KPK, Pakistan [24] inducing mosaic symptoms that later on turns into yellow mosaic (Figure 1a), mottle and severe puckering. In an attempt to obtain mild isolate for cross-protection, assay hosts including $C$. amaranticolor, C. quinoa, N. benthamiana, N. Glutinosa, N. Rustica, $C$. sativus and $V$. unguiculata were mechanically inoculated with CGMMV. No satisfactory local lesion host could be found in this assay. Hence C. sativus was finally selected to be used as host for low temperature treatment and also for the mild strain selection. After low temperature treatment, the isolate was rub inoculated onto 200 healthy C. sativus seedlings at single leaf stage and were kept in greenhouse under flruorescent light. Regular selection was done on the basis of symptom development. Almost half of the plants, being grown for mild strain selection, were discarded due to appearance of severe symptoms in the normal course of time. Out of the remaining plants (97), 15 were having no symptoms and were negative in serological assay (DIBA), indicating that these plant actually, for some reason, escaped infection with the mild strain. Also, no virus particle could be detected in samples from these plants in electron microscopy. Thirteen plants were
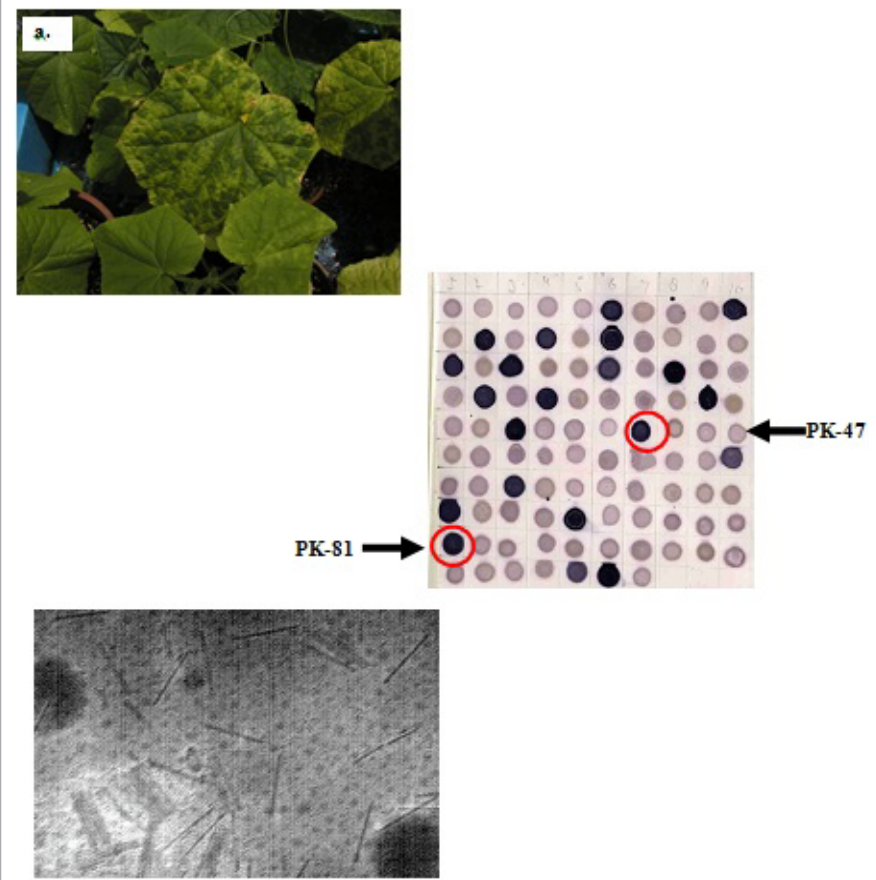

Figure 1: (a) Symptoms produced by Cucumber green mottle mosaic virus on C. sativus plants. (b) Serological assay (DIBA) showing the results of mild strain selection of CGMMV-Pk isolate treated at low temperature $\left(12-16^{\circ} \mathrm{C}\right)$. Isolate number 47 and 81 were giving very strong positive signal in DIBA assay, but no symptoms on C. sativus plants. (c) Electron micrograph of C. sativus sample infected with mild strain $\mathrm{Pk}-47$, showing large number of CGMMV viral particles. 
Citation: Ali A, Ahmad M, Nishigawa H, Natsuaki T (2015) Evaluation of Low Temperature Induced Mutants of Cucumber green mottle mosaic virus for Cross-protection in Cucurbits. J Plant Pathol Microbiol S3: 010. doi:10.4172/2157-7471.S3-010

showing moderate symptoms of green mosaic and were positive in DIBA assay also. Around 48 plants were showing very mild symptoms, but also very mild positive dot in the serological assay, indicating that the mild symptoms are just because of low virus concentration. Very strong positive results in DIBA analysis were observed from 21 plants. Among these 21 plants, only two were showing no symptoms and very strong positive result in serological analysis (Figure 1b). When checked under electron microscope, both the plant samples were having very high concentration of virus particles (Figure 1c). These two isolates, designated hereafter as Pk-47 (Figure 2a) and Pk-81(Figure 2b), were selected for subsequent experiments on cross-protection.

\section{Cross-protection under greenhouse conditions}

In greenhouse experiments, the control plants started developing symptoms just 5 days after inoculation and were exhibiting severe symptoms in 10-12 days post challenge inoculation (Figure 3c). Plants inoculated with Pk-47 isolate initially developed very mild symptoms that disappeared in one week post inoculation period. In crossprotection test, with the two selected isolates, symptoms developed in plants that were challenge-inoculated 5 or 7 days post protectioninoculation. Those plants that were given challenge-inoculation 10 days after the protection-inoculation did develop some mild symptoms, but later on they showed recovery and the symptoms disappeared from the $3^{\text {rd }}$ or $4^{\text {th }}$ leaf after challenge-inoculated leaf. In all other treatments (challenge-inoculation done after 15, 20 and 25 days post protection-inoculation) both the $\mathrm{Pk}-47$ and $\mathrm{Pk}-81$ mild isolates were exhibiting convincing protection abilities to control the severe strain of CGMMV-Pk. The effectiveness of the cross-protection was evaluated at three different temperatures $\left(17-22^{\circ} \mathrm{C}, 22-27^{\circ} \mathrm{C}\right.$ and $\left.27-32^{\circ} \mathrm{C}\right)$, and it was observed that it worked equally well under all the experimental conditions (Figure $3 \mathrm{a}$ and $3 \mathrm{~b}$ ). Among the two isolates, protection abilities of $\mathrm{Pk}-81$ seemed to be more promising comparing to $\mathrm{Pk}-47$. All the plants remained symptom-less, for almost two months, after the challenge inoculation. Observations could not be prolonged as limited growing media and rapid growth of the host plants hindered
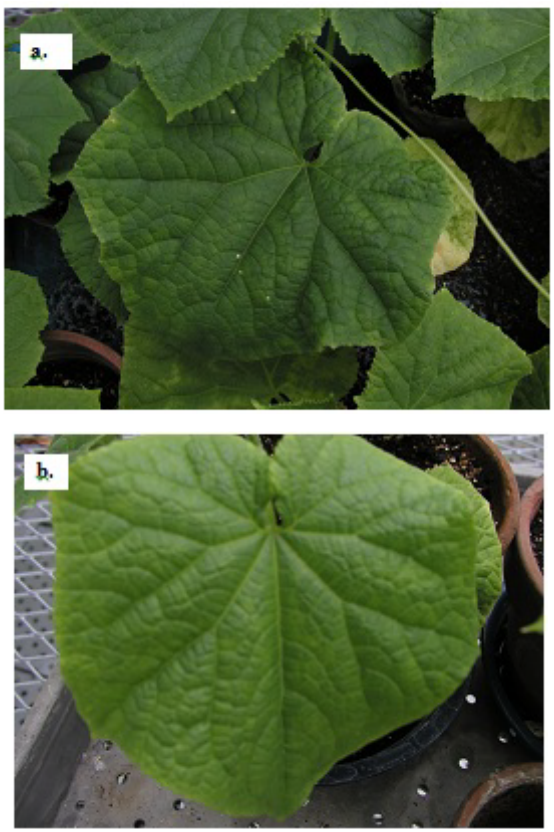

Figure 2: Mild strains of CGMMV-Pk selected at low temperature $\left(12-16^{\circ} \mathrm{C}\right)$ treatment for 45 days. (a) Isolate Pk-47 and (b) Isolate Pk-81.
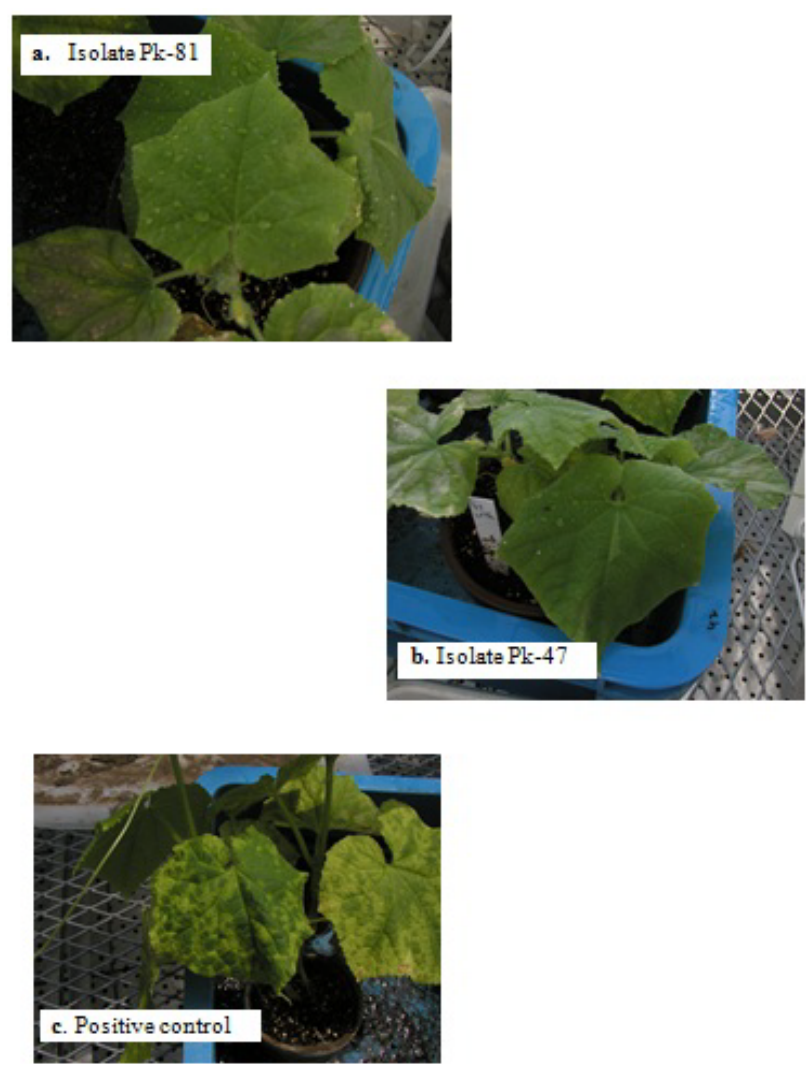

Figure 3: Efficacy of cross-protection abilities of two mild isolates, (a) Pk-47 and (b) $\mathrm{Pk}-81$, induced by low temperature treatment in $C$. sativus plants. (c) Severe strain of CGMMV inducing characteristic symptoms on $C$. sativus in positive control.

continuation. After two months natural senescence of the plants could be seen in negative control as well as in the protected plants. The experimental results revealed that protection inoculation at least 15 days prior to challenge inoculation will serve better. Due to time limitation, experiments could not be planed to test the efficiency of protection under different disease pressures as well as to figure out the beneficial effects of control on yield and yield components, nor could it be evaluated under natural field conditions. This pilot study provided a good nucleus material that can be used in subsequent experiments to fully characterize the isolates, before recommending it for commercial growth.

\section{Discussion}

Etiology of the viral disease of cucurbit crops, prevalent in KPK, Pakistan, revealed that the mosaic disease is caused by complex of different viruses. Five viruses were found infecting the crops, with CGMMV being the most widespread [24]. The dominance of CGMMV could be attributed to the contact transmission of the virus, coupled with the poor phytosanitary measures. The farmers in the area have little or no knowledge of viral diseases or their mode of transmission and spread. Most of the farmers use their own seeds or seeds from uncertified agencies without due regard for the health and purity of the seeds. The connecting irrigation channels among the fields and use of contaminated tools exacerbate the situation.

Cross-protection has long been demonstrated as an effective control for plant viruses as well as other classes of plant pathogens and at times it was believed to be analogous to the immunity developed in mammals 
Citation: Ali A, Ahmad M, Nishigawa H, Natsuaki T (2015) Evaluation of Low Temperature Induced Mutants of Cucumber green mottle mosaic virus for Cross-protection in Cucurbits. J Plant Pathol Microbiol S3: 010. doi:10.4172/2157-7471.S3-010

following vaccination, although its mechanism does not involve the formation of antibodies [4]. PTGS is a common plant defense response active against diverse viruses and likely to play an important role in cross-protection [6,7]. Low temperature treatment has been found effective to induce mutation [13]. We successfully obtained two mild isolates Pk-47 and Pk-81 from the severe strain of CGMMV-Pk by subjecting it to low temperature treatment. It has been observed that a certain time interval between the protection and challenge-inoculation is required to establish cross-protection, and the degree of crossprotection is related to the concentration of the protecting virus in the plants $[10,11,25]$. Our preliminary data also supports this conclusion however; it needs to check the effect of inoculum's concentration (both protecting and challenge isolate) in our case.

One of the major concerns in using mild strain for cross-protection is the effect that this virus may cause in association with other viruses under natural field conditions and also on other host crops in the vicinity. Therefore, there is a dire need to evaluate this type of synergistic association with other viruses, before recommending it for control in commercial farmer's fields. Multiple inoculations of mild isolates of different viruses have been investigated and were found effective [14]. Efforts could be directed to induce mild strains for other prevalent viruses also, to help farmer controlling the complex of viruses under field conditions or at least minimizing the detrimental effects to economic beneficial level.

Another limitation for making cross-protection as the method of choice is the excessive labour cost and long time required to inoculate mild strain for protection purposes. CGMMV is a contact transmitted virus, once the mild strains are fully characterized, they can easily be used on large scale for protection with least cost. Even seed treatment may provide an easy and feasible mean of inoculating the crops. Spray gun can also be used for effective inoculation of the plants at seedling stage and this method would avoid the possibility of mechanical transmission of any severe strains of the virus present in the seedlings population. Also, in this case if few seedlings escape spray inoculation with the mild strain, they would be subsequently infected during the cultural practices from the adjacent abundant source of inocula. The stability of the mild strain in this case should not be a concern as tobamoviruses are known to have the most stable genome among the plant viruses, but one must always need to take the necessary precautions by continually evaluating the actual inocula used for crossprotection. Although, the previous findings Ali et al., [24] indicate very low level of diversity in the sequence of CGMMV isolates reported so far, one must also investigate the diversity of the virus in the area concerned. Some sort of variability do occur in genome of CGMMV, which is also reflected by different symptom expressions reported for watermelon isolate from Japan and CGMMV-Pk. Watermelon strain recorded in Japan [26] induce local lesions in C. amaranticolor, but CGMMV-Pk did not produce any such symptom in C. amaranticolor. Low diversity mean effective control, on the other hand, if there is a diverse population in the area it would probably make cross-protection a bit ineffective. It has been demonstrated that mild PRV-HA 5-1, which provided the CP gene of the line 55-1 from Hawaii, do not offer protection against PRV isolates from Thailand and only limited protection against those from Taiwan [9,27].

Genetic resistance and use of transgenic material would be the priority method to control, if available, but use of cross protection is also effective and excellent control have been reported in many viral diseases; PRSV [9,11,27], WMV [12], CMV [14,15], TMV [16-18], CTV [19], ZYMV [20] and ToMV [22]. Moreover, the reluctance of consumers in using the harvest of genetically modified crops will make it a preferred strategy for controlling viral diseases. Careful attention to selection of the best protective isolates of virus and their introduction into the crop to be protected are essential. We would like to characterize these two isolates under natural field conditions to study their effect on the adjacent crops, and also their interaction with the prevalent viruses in the region. Once established, these mild isolates can subsequently be used at commercial scale for controlling the prevalent CGMMV infection in cucurbit crops of the region. Other control strategies may also be tried along with the mild strain protection to formulate an effective integrated approach for successfully controlling the mosaic disease in the cucurbit crops of Pakistan.

\section{References}

1. Mckinney HH (1929) Mosaic disease in the Canary Islands, West Africa, and Gibraltar. J Agric Res 39: 557-578.

2. Dodds JA, Lee SQ, Tiffany M (1985) Cross protection between strains of cucumber mosaic virus: effect of host and type of inoculum on accumulation of virions and double-stranded RNA of the challenge strain. Virology 144: 301309.

3. Watanabe $\mathrm{Y}$, Morita N, Nishiguchi M, Okada Y (1987) Attenuated strains of tobacco mosaic virus. Reduced synthesis of a viral protein with a cell-to-cell movement function. J Mol Biol 194: 699-704

4. Fulton RW (1986) Practices and precautions in the use of cross-protection for plant virus disease control. Ann Rev Phytopathol 24: 67-81.

5. Palukaitis $P$, Zaitlin $M$ (1984) A model to explain the cross-protection phenomenon shown by plant viruses and viroids. In: Kosuge T, Nester EW (eds) Plant-Microbe Interactions. Vol. 1. Molecular and Genetic Perspectives. Mac Millan, NY, pp. 420-429.

6. Dougherty WG, Parks TD (1995) Transgenes and gene suppression: telling us something new? Curr Opin Cell Biol 7: 399-405.

7. Baulcombe D (1999) Viruses and gene silencing in plants. Arch Virol Suppl 15: 189-201.

8. Rezende JAM, Urban L, Sherwood JL, Melcher U (1992) Host effect on crossprotection between two strains of Tobacco mosaic virus. J Phytopathol 136 147-153.

9. Wang HL, Yeh SD, Chiu RJ, Gonsalves D (1987) Effectiveness of crossprotection by mild mutants of Papaya ringspot virus for control of ringspot disease of papaya in Taiwan. Plant Dis 71: 491-497.

10. Yeh SD, Gonsalves D (1984) Evaluation of induced mutants of Papaya ringspot virus for control by cross-protection. Phytopathology 74: 1086-1091.

11. Huogen X, Hweichung F, Kunghsun L (1995) Studies on the cross-protection among strains of Papaya ringspot virus and its application in the disease control. In: Proc Int Workshop on the Pest Management Strategies in Asian Monsoon Agroecosystems, pp. 281-291.

12. Kameya-Iwaki M (1994) Control of virus disease by attenuated viruses. Agric Hortic 69: 137-142.

13. Kosaka Y, Fukunishi T (1993) Attenuated isolates of Soybean mosaic virus derived at low temperature. Plant Dis 77: 882-886.

14. Kosaka Y, Fukunishi T (1997) Multiple inoculations with three attenuated viruses for the control of Cucumber virus disease. Plant Dis 81: 733-738.

15. Montasser MS, Tousignant ME, Kaper JM (1998) Viral satellite RNAs for the prevention of Cucumber mosaic virus disease in field grown pepper and melon plants. Plant Dis 82: 1298-1303.

16. Fletcher JT (1978) The use of avirulent virus strains to protect plants against the effects of virulent strains. Ann Appl Biol 89: 110-114.

17. Oshima N (1975) The control of tomato mosaic disease with attenuated virus of a tomato strain of TMV. Rev Plant Prot Res 8: 126-135.

18. Rast ATB (1972) MII, an aritificial symptomless mutant of Tobacco mosaic virus for seedling inoculation of tomato crops. Netherlands J plant Pathology 78:110120

19. Muller GW, Costa AS (1977) Tristeza control in Brazil by preimmunization with mild strains. Proc. Int. Soc. Citriculture 3: 868-872. 
Citation: Ali A, Ahmad M, Nishigawa H, Natsuaki T (2015) Evaluation of Low Temperature Induced Mutants of Cucumber green mottle mosaic virus for Cross-protection in Cucurbits. J Plant Pathol Microbiol S3: 010. doi:10.4172/2157-7471.S3-010

20. Lecoq H, Lemaire JM, Wipf-Scheibel C (1991) Control of Zucchini yellow mosaic virus in squash by cross-protection. Plant Dis $75: 208-211$

21. Sterk P, Jager CP (1987) Interference between Cowpea mosaic virus and Cowpea severe mosaic virus in a Cowpea host immune to Cowpea mosaic virus. J Gen Virol 68; 2751-2758.

22. Zhang XH, Li GX, Liang XX, Tien P (1980) The avirulent strain of plant virus and its application: $I$. The induction of avirulent strain of ToMV and some of its properties. Acta Phytopathol Sinica 10: 49-54.

23. Ali A, Randles JW (1997) Early season survey of pea viruses in Pakistan and the detection of two new pathotypes of Pea seedborne mosaic potyvirus. Plant Dis 81: $343-347$.
24. Ali A, Natsuaki T, Okuda S (2004) Identification and molecular characterization of viruses infecting cucurbits in Pakistan. J Phytopathol 152: 677-682.

25. Wen F, Lister RM, Fattouh FA (1991) Cross-protection among strains of barley yellow dwarf virus. J Gen Virol 72: 791-799.

26. Komuro Y, Tochihara H, Fukatsu R, Nagai Y, Yuneyama S (1971) Cucumber green mottle mosaic virus in watermelon and its bearing on deterioration of watermelon fruit known Konnyyaku disease. Ann Phytopathol Soc Japan 37 34-42. (in Japanese)

27. Yeh SD, Gonsalves D (1994) Practices and perspective of control of Papaya ringspot virus by cross-protection. In: Advances in Disease Vector Research. 